H. R. Rugge and D. I. McKenzie Space Sciences Laboratory The Aerospace Corporation

Los Angeles, $\mathrm{CA}$

The SOLEX bragg crystal spectrometer experiment on the P78-1 satellite (Landecker, McKenzie and Rugge, 1979) has been used to determine accurate flux ratios of several strong solar Fe XVII x-ray emission lines in the $\sim 15$ to $\sim 17 \AA$ wavelength region. The ratios chosen were selected because the lines used permitted an accurate determination of the ratios both from the aspect of counting statistics as well as the lack of interference from other lines of comparable strength. Observations for a variety of conditions of solar activity, ranging from quiet conditions to large solar flares, are presented. For these observations intensity variations of a factor of about 60 were observed for the Fe XVII lines. Variations of a factor of almost 800 were observed for the Fe XVIII line at $14.2 \AA$. The observed ratios of the Fe XVII lines are compared to the theories of Loulergue and Nussbaumer (1975) and Smith, Raymond, Mann and Cowan (1984).

Agreement between the observed values of the ratios and the mean theoretical values is, in general, acceptable. However agreement between observation and theory for the ratios as a function of solar activity is not good. The observations further show that ratios involving the $15.01 \AA \mathrm{Fe}$ XVII resonance line show greater variability than predicted by theory or than observed in other ratios. This may be evidence for resonance absorption cf this line in the active region producing it.

The values and variability of the important line ratios are presented below as a function of parameters involving $\mathrm{Fe}$ XVII and $\mathrm{Fe}$ XVIII lines and line ratios used to characterize solar activity. There is little systematic dependence on solar activity in these ratios as characterized by flux in a resonance line of Fe XVIII (14.2 $)$ or the Fe XVIII (14.2 )/Fe XVII (17.04 ) flux ratio.

\title{
REFERENCES
}

Landecker, P.B., Mckenzie, D.L., and Rugge, H.R., 1979, Proc: S.P.I.E., 184,285 .

Loulergue, M. and Nussbaumer, H., 1975, Astron. and Astrophys. 45, 125.

Smith, B.W., Raymond, J.C., Mann, J.B. and Cowan, R.D., 1984, Los Alamos Preprint-LA-LR-84-1355. 
Fig. 1 A typical spectrum used to determine line intensities and ratios. Most active region spectra (14.2 $\AA$ flux $\lesssim 150 \mathrm{x}$ $\left.10^{3} \mathrm{ph} \mathrm{cm}^{-2} \mathrm{~s}^{-1}\right)$ used sums of about 10 scans. Flare ratios were determined using individual scans.

Fig. $2 \quad 16.77 \AA$ to $17.04 \AA$ intensity ratios for 46 observations. Figs. 2, 3 and 4 use the same scales so that the variability of the ratios can be easily compared.

Fig. $3 \quad 17.04 \AA$ to $15.01 \AA$ intensity ratios for 46 observations. Note the substantially greater variation in the ratios as compared to Figures 2 and 4 .

Fig. $4 \quad 17.04 \AA$ to $17.09 \AA$ intensity ratios for 46 observations. There is essentially no change in the ratio with solar activity.

Fig. 5 A comparison of the observed ratios with those predicted by two independent theoretical calculations.

Solex Spectrum

REV 2608 SUM OF 14 SCANS

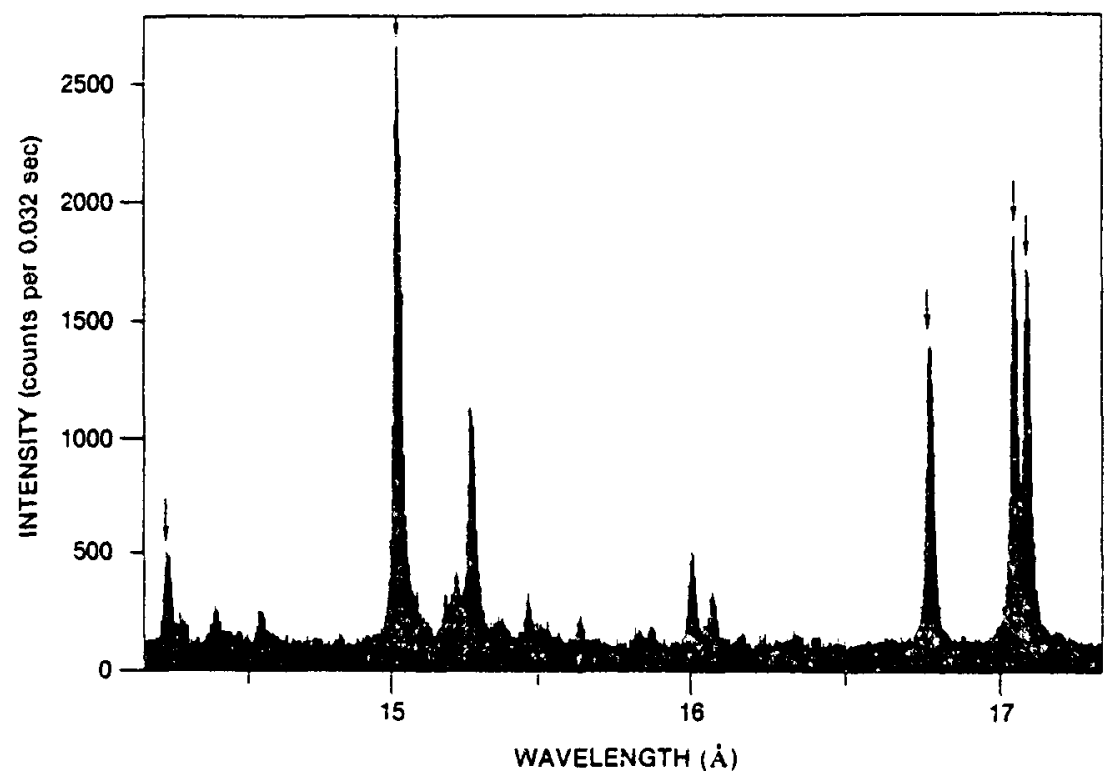

Figure 1 

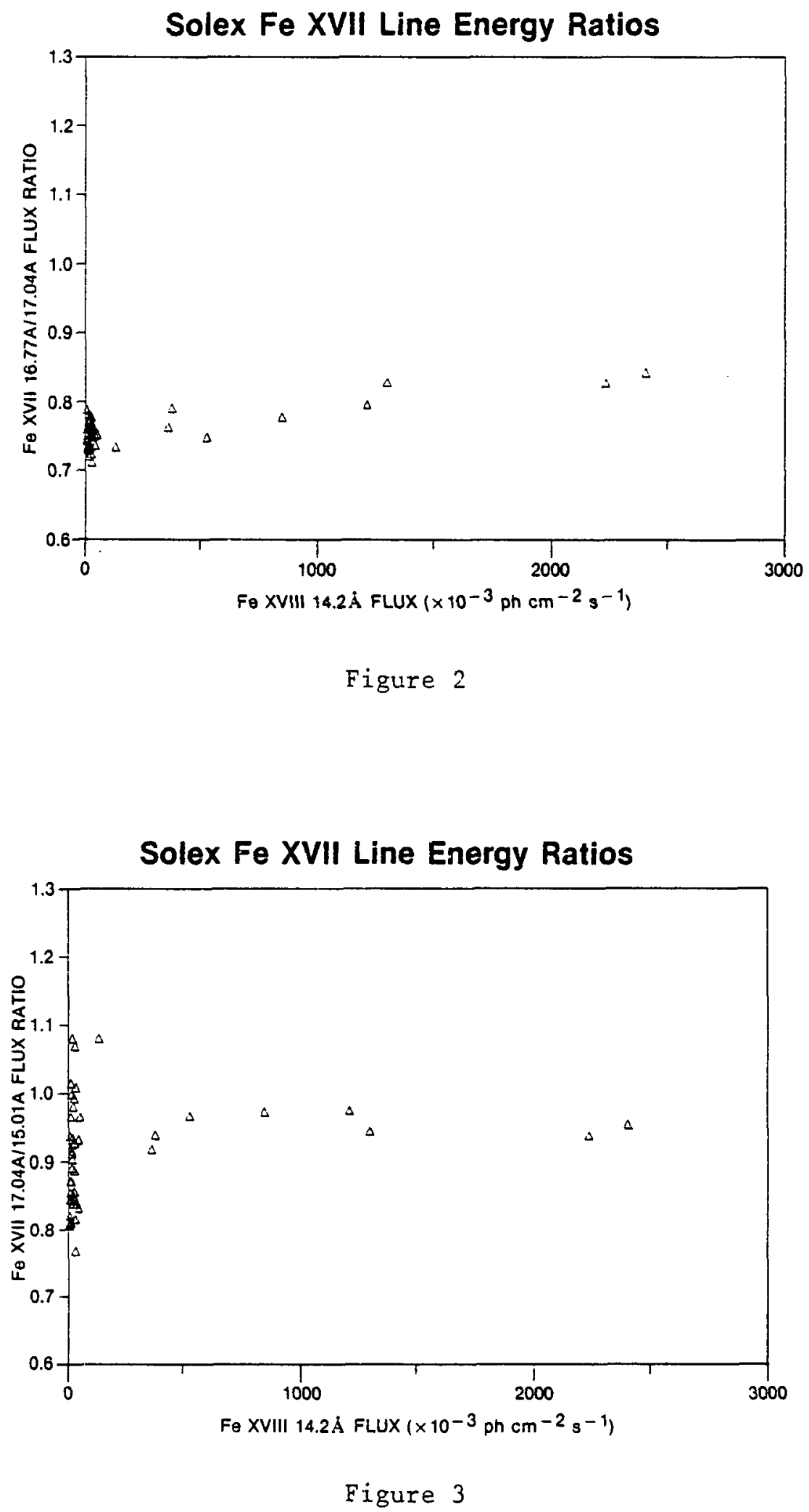


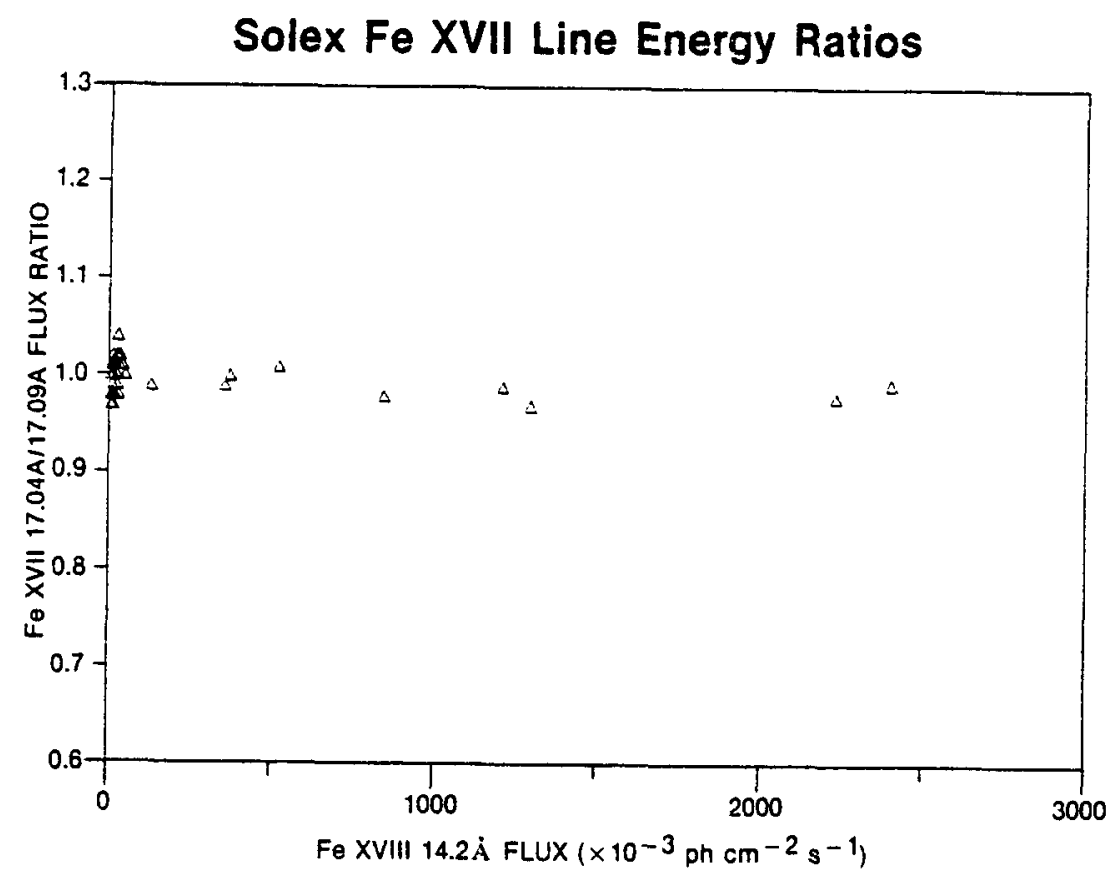

Figure 4

\section{Comparison of Theory and Observations}

\begin{tabular}{|c|c|c|c|}
\hline AUTHORS & \multicolumn{3}{|c|}{ ENERGY RATIOS } \\
\hline & $16.77 \mathrm{~A} / 17.04 \mathrm{~A}$ & $17.04 \mathrm{~A} / 17.09 \mathrm{~A}$ & $17.04 \mathrm{~A} / 15.01 \mathrm{~A}$ \\
\hline $\begin{array}{l}\text { RUGGE and MCKENZIE } \\
\text { THIS WORK (1984) }\end{array}$ & $0.75 \rightarrow^{2}$ & $1.00 \rightarrow د$ & $0.91 \longrightarrow \Delta$ \\
\hline $\begin{array}{l}\text { LOULERGUE and NUSSBAUMER* } \\
\text { As. Ap. } 45,125 \text { (1975) }\end{array}$ & $0.64^{+} \geq \Delta$ & $1.29 \longrightarrow \Delta$ & $0.86^{+}-$ \\
\hline \multirow[t]{6}{*}{$\begin{array}{l}\text { SMITH, RAYMOND, MANN } \\
\text { and COWAN" } \\
\text { LANL PREPRINT (1984) }\end{array}$} & & 1.32 & $0.61^{+}$ \\
\hline & \multicolumn{3}{|c|}{ Fe XVII TRANSITIONS } \\
\hline & $15.01 \mathrm{~A} 1 \mathrm{~s}$ & \multirow{4}{*}{\multicolumn{2}{|c|}{$\begin{array}{l}1 s^{2} 2 s^{2} 2 p^{6} 1 s_{0}-1 s^{2} 2 s^{2} 2 p^{5} 3 d^{1} p_{1} \\
1 s^{2} 2 s^{2} 2 p^{6} 1 s_{0}-1 s^{2} 2 s^{2} 2 p^{5} 3 s{ }^{1} p_{1} \\
1 s^{2} 2 s^{2} 2 p^{6}{ }^{1} s_{0}-1 s^{2} 2 s^{4} 2 p p_{3 s}{ }^{3} p_{1} \\
1 s^{2} 2 s^{2} 2 p^{6}{ }^{1} s_{0}-1 s^{2} 2 s^{2} 2 p^{5} 3 d^{3} p_{2}\end{array}$}} \\
\hline & $16.77 \mathrm{~A}$ is & & \\
\hline & $17.04 \mathrm{~A}$ is & & \\
\hline & $17.09 \mathrm{~A}$ is & & \\
\hline
\end{tabular}

"CALCULATION For T $=5 \times 10^{6}$ ० $\mathrm{K}$

+"17.04A" FLUX USED $=(17.04 A+17.09 A$ FLUX $) \div 2$

$\triangle$ ARROWS INDICATE TREND WITH INCREASING TEMPERATURE

Figure 5 